\title{
$17 \beta$-estradiol lowers triglycerides in adipocytes via estrogen receptor $\alpha$ and it may be attenuated by inflammation
}

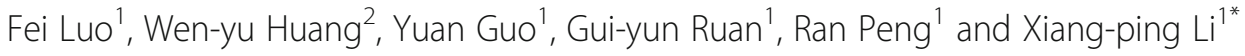

\begin{abstract}
Background: Estrogen was reported to protect against obesity, however the mechanism remains unclear. We aimed to investigate the impact of $17 \beta$-estradiol (17ß-E2) on triglyceride metabolism in adipocytes with or without lipopolysacchride (LPS) stimulating, providing novel potential mechanism for estrogen action.

Methods: 3T3-L1 adipocytes were cultured and differentiated into mature adipocytes in vitro. The differentiated 3T3L1 cells were divided into six groups: (i) control group, treated with 0.1\% DMSO alone; (ii) 17ß-E2 group, treated with 1, 0.1, or $0.001 \mu \mathrm{M} 17 \beta$-E2 for $48 \mathrm{~h}$; (iii) 17ß-E2 plus MPP group, pre-treated with $10 \mu \mathrm{M}$ MPP (a selective ERa receptor inhibitor) for $1 \mathrm{~h}$, then incubated with $1 \mu \mathrm{M} 17 \beta$-E2 for 48 h; (iv) 17ß-E2 plus PHTPP group, pre-treated with $10 \mu \mathrm{M}$ PHTPP (a selective ER $\beta$ receptor inhibitor), then incubated with $1 \mu \mathrm{M} 17 \beta$-E2 for $48 \mathrm{~h}$; (v) LPS group, pre-treated with $100 \mathrm{ng} / \mathrm{mL}$ LPS for $24 \mathrm{~h}$, then cells were washed by PBS for 3 times and incubated with $0.1 \%$ DMSO alone for 48 h; (vi) 17ß-E2 plus LPS group, pre-treated with $100 \mathrm{ng} / \mathrm{mL}$ LPS for $24 \mathrm{~h}$, then cells were washed by PBS for 3 times and incubated with $1 \mu \mathrm{M} 17 \beta$-E2 for $48 \mathrm{~h}$. The levels of triglyceride and adipose triglyceride lipase (ATGL) in differentiated 3T3-L1 cells and the concentrations of interleukin-6 (IL-6) in culture medium were measured.
\end{abstract}

Results: Comparing with control group, $1 \mu \mathrm{M}$ and $0.1 \mu \mathrm{M}$ 17ß-E2 decreased the intracellular TG levels by about 20\% and $10 \%$ respectively (all $P<0.05$ ). The triglyceride-lowing effect of 17ß-E2 in differentiated 3T3-L1 cells was abolished by ERa antagonist MPP but not ER $\beta$ antagonist PHTPP. Comparing with control group, the IL-6 levels were significantly higher in the culture medium of the cultured differentiated 3T3-L1 cells in LPS group and 173-E2 + LPS group (all $P<0.05$ ). And, the IL-6 levels were similar in LPS group and 17 $\beta-E 2+$ LPS group $(P>0.05)$. There was no significant difference in the triglyceride contents of differentiated 3T3-L1 cells among control group, LPS group and 17 $\beta$-E2 + LPS group (all $P>0.05$ ). ATGL expression in 17 $\beta$-E2 group was significantly higher than control group $(P<0.05)$, which was abolished by ERa antagonist MPP or LPS.

Conclusions: $17 \beta-E 2$ increased ATGL expression and lowered triglycerides in adipocytes but not in LPS stimulated adipocytes via estrogen ERa.

Keywords: $17 \beta$-estradiol, Adipocyte, Triglyceride, Estrogen receptor a

\footnotetext{
* Correspondence: lixp0040@sina.com; lixp0040@csu.edu.cn

'Department of Cardiovascular Medicine, The Second Xiangya Hospital,

Central South University, No.139 Renmin Middle Road, Changsha 410011,

Hunan, People's Republic of China

Full list of author information is available at the end of the article
} 


\section{Background}

Obesity is considered as an abnormal or excessive fat accumulation and it is one of the most important disturbances associated with the menopausal. The incidence of obesity in women at the age of 40 to 65 is up to $65 \%$ [1]. Previous studies reported the prevalence of obesity and metabolic syndrome in menopausal women is 3.3-fold higher among postmenopausal women than premenopausal women. Donato et al. reported postmenopausal women have five times the chance of having central adiposity than premenopausal women, even after controlling for BMI and other confounding factors [2]. And adiposity in postmenopausal women can be attenuated by estradiol replacement therapy [3]. In rodents, ovariectomy result in a significant weight gain and which can be reversed with the administration of exogenous estradiol [4-6]. Accordingly, this evidence indicates the rapid decline of estrogen levels contributes to obesity and estrogen can protect against obesity. However, the anti-obesity mechanism of estradiol is still unclear.

Obesity is ascribed to an imbalance between energy intake and expenditure and is characterized by increased storage of triglyceride (TG) in an expanded adipose tissue mass [7]. Inhibition of TG accumulation in adipocyte is an important key to attenuate obesity. Previous studies have reported estrogen could regulate plasma TG level [8]. Lack of estrogen in post-menopausal women leads to an increase in plasma TG and transdermal estradiol treatment for post-menopausal women could lower plasma TG levels by about $16.4 \%(P<0.01)$ [9-11]. However, the anti-obesity effect of estradiol cannot be fully explained by its impact on plasma TG levels [6]. Besides, it was reported estradiol has apparent effect on intracellular TG metabolism beyond its intravascular effect. Study reported $17 \beta$-estradiol $(17 \beta-E 2)$ reduces TG levels in the liver by inhibiting liver $X$ receptor (LXR) activation [12]. Zhang et al. reported that estradiol significantly reduces TG accumulation in mouse embryonic fibroblasts [13]. This evidence indicated estradiol directly regulates intracellular TG accumulation, but the underlying mechanisms remain to be fully elucidated. It is believed that obesity is also a state of chronic inflammation [14]. Therefore, we wonder whether the inflammation will affect the effect of estradiol on TG in adipocyte. We designed the experiment to study the effects of estradiol on TG contents of adipocytes with or without inflammatory conditions in vitro.

\section{Methods}

\section{Cell culture and differentiation}

The 3T3-L1 cells were obtained from the American Type Culture Collection (ATCC, Rockville, USA) and cultured in Dulbecco modified eagle medium (DMEM, GIBICO, Invitrogen corporation, Changsha, china) supplemented with $10 \%$ fetal bovine serum (FBS, Sigma-Aldrich, St. Louis, MO, USA) at $37{ }^{\circ} \mathrm{C}$ under a humidified atmosphere of 5\% CO2 and 95\% air. Differentiation of 3T3-L1 cells to mature adipocytes was performed as previous described [15]. Briefly, 3T3-L1 cells were seeded at 6-well plate and stimulated with $0.4 \mathrm{mmol} / \mathrm{L} 3$-isobutyl-1-methylxanthine (IBMX) (Sigma-Aldrich), $0.25 \mu \mathrm{mol} / \mathrm{L}$ dexamethasone (Dex, Sigma-Aldrich) and $10 \mu \mathrm{g} / \mathrm{mL}$ insulin (SigmaAldrich) in DMEM containing 10\% FBS for $72 \mathrm{~h}$. Then, cells were cultured with $10 \mu \mathrm{g} / \mathrm{mL}$ insulin alone in DMEM containing 10\% FBS for another $8 \mathrm{~d}$. The cell-culture medium was replenished every other day. Approximately 90\% of the 3T3-L1 cells had differentiated into mature adipocytes on day 12 .

\section{Cell treatment}

Differentiated 3T3-L1 adipocytes were starved in serum free DMEM for $12 \mathrm{~h}$ and then were divided into six groups: (i) control group, treated with $0.1 \%$ DMSO alone; (ii) $17 \beta$-E2 group, treated with $1,0.1$, or $0.001 \mu \mathrm{M}$ $17 \beta-E 2$ (Abcam, Cambridge, UK) for $48 \mathrm{~h}$; (iii) $17 \beta-\mathrm{E} 2$ plus MPP group, pre-treated with $10 \mu \mathrm{M}$ MPP (a selective ER $\alpha$ receptor inhibitor, Tocris Bioscience, Bristol, UK) for $1 \mathrm{~h}$, then incubated with $1 \mu \mathrm{M} 17 \beta$-E2 for $48 \mathrm{~h}$; (iv) $17 \beta$-E2 plus PHTPP group, pre-treated with $10 \mu \mathrm{M}$ PHTPP (a selective ER $\beta$ receptor inhibitor, Tocris Bioscience, Bristol, UK), then incubated with $1 \mu \mathrm{M} 17 \beta$ E2 for $48 \mathrm{~h}$; (v) LPS group, pre-treated with $100 \mathrm{ng} / \mathrm{mL}$ lipopolysaccharide (LPS) for $24 \mathrm{~h}$, then cells were washed by PBS for 3 times and incubated with $0.1 \%$ DMSO alone for $48 \mathrm{~h}$; (vi) 17ß-E2 plus LPS group, pretreated with $100 \mathrm{ng} / \mathrm{mL}$ LPS for $24 \mathrm{~h}$, then cells were washed by PBS for 3 times and incubated with $1 \mu \mathrm{M}$ $17 \beta-\mathrm{E} 2$ for $48 \mathrm{~h}$.

\section{Triglyceride and IL-6 quantification}

Triglyceride contents in adipocytes and IL-6 levels in supernatant were separately measured using triglyceride assay kit (BioVision, Mannheim, San Francisco, USA) and IL-6 assay kit (Wuhan xinqidi Biological, Wu-Han, China) according to the manufacturers' instructions.

\section{Western blotting}

Western blotting was performed as previous described [16]. Briefly, the proteins from differentiated 3T3-L1 adipocytes were extracted with RIPA lysis buffer (Beyotime, Beijing, China) and separated on sodium dodecyl sulfate-polyacrylamide gel electrophoresis (SDS-PAGE) before transferring on to polyvinylidene difluoride (PVDF) membranes. Then, the membranes were blocked and then incubated with the following antibodies: mouse monoclonal anti-ATGL (Abcam, Cambridge) at $4{ }^{\circ} \mathrm{C}$ for overnight. Blots were washed, incubated with secondary antibody, and visualized by chemiluminescence. 


\section{Statistical analysis}

All values are expressed as mean \pm standard deviation (SD) and analyzed by One-way analysis of variance (ANOVA) and Student's t-test, using SPSS 20.0 statistical software (SPSS Inc., Chicago, IL, USA). $P<0.05$ (two sided) was considered as statistically significant.

\section{Results}

\section{$17 \beta$-E2 lowers triglyceride content in differentiated}

\section{T3-L1 cells}

To investigate the effect of $17 \beta-\mathrm{E} 2$ on TG content of differentiated 3T3-L1 cells, the TG levels in adipocytes were determined after treatment with different concentrations of $17 \beta-E 2$ for $48 \mathrm{~h}$. We observed that $17 \beta-\mathrm{E} 2$ significantly decreased intracellular TG levels in a dosedependent manner (Fig. 1).

17 $\beta$-E2 lowers triglyceride content in differentiated 3T3-L1 cells possibly via ERa

Estrogen receptor $\alpha(E R \alpha)$ and $\operatorname{ER} \beta$ are the main estrogen receptors, we used selective receptor inhibitors to investigate the role of them in the TG-lowing effect of $17 \beta-E 2$. The triglyceride-lowing effect of 17ß-E2 in differentiated 3T3-L1 cells was abolished by ER $\alpha$ antagonist MPP, while ER $\beta$ antagonist PHTPP did not significantly affect the TG-lowing effect (Fig. 2).

$17 \beta-E 2$ did not affect triglyceride content in differentiated 3T3-L1 cells on inflammatory state

Inflammation and its failure to resolve are firmly established as central to the development and complications of several cardiovascular diseases [17]. We used the LPS-stimulated 3T3-L1 cell line as an inflammatory model and evaluated the effect of $17 \beta-\mathrm{E} 2$ on TG content

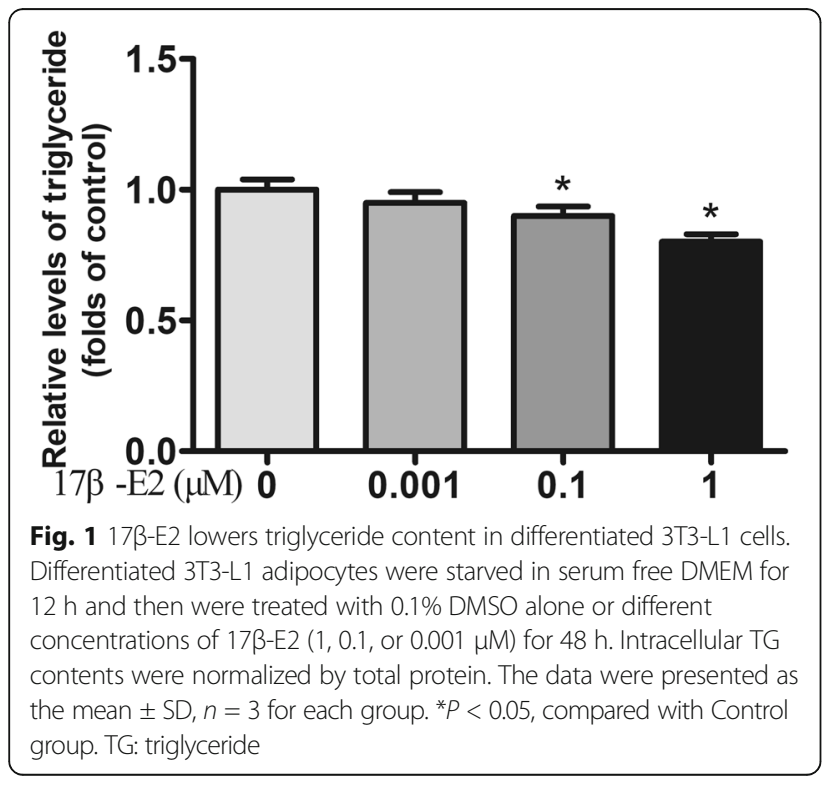

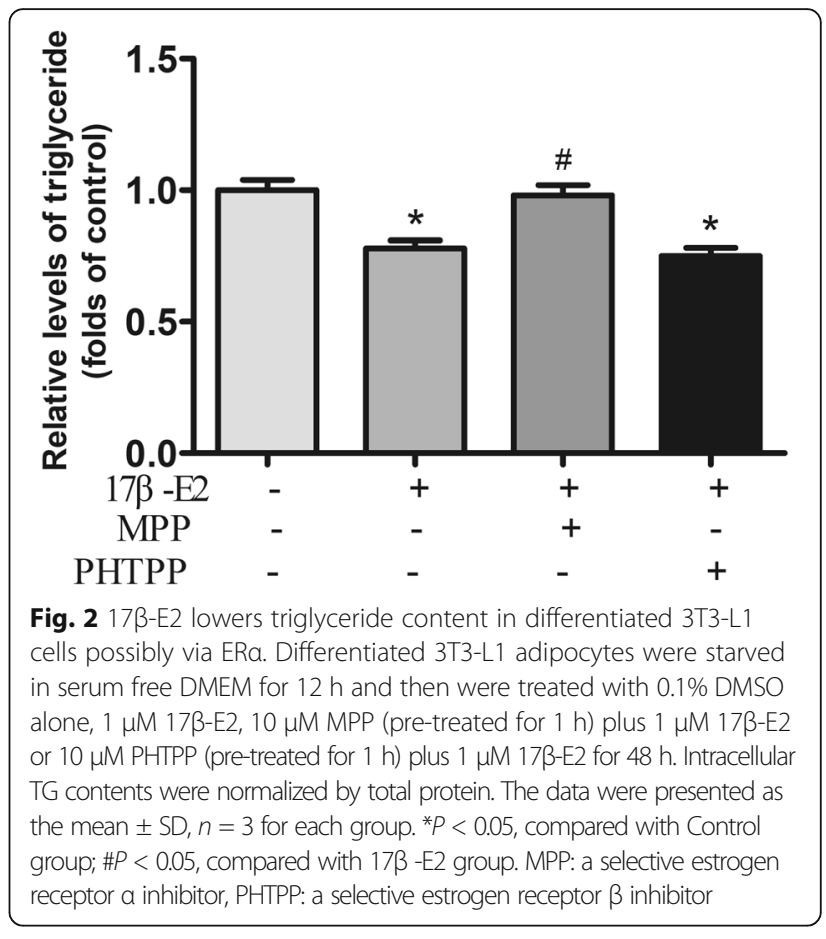

of differentiated 3T3-L1 cells when exposed to LPS. LPS to induce inflammation response, as shown in Fig. 2, LPS (100 ng/mL) significantly increased IL-6 levels in feeder cell culture supernatants in LPS group and $17 \beta$ E2 + LPS group, compared with control group (Fig. 3a). There was no significant difference between control group, LPS group and LPS + 17 $\beta$-E2 group for TG content of differentiated 3T3-L1 cells (Fig. 3b).

\section{7 $\beta$-E2 increased ATGL expression in differentiated 3T3-L1} cells via ERa

Adipose triglyceride lipase (ATGL) is an important regulator in TG hydrolysis. We evaluated the effect of $17 \beta$ E2 on ATGL expression. We found ATGL expression in $17 \beta$-E2 group was significantly higher than control group (Fig. 4). The upregulation of ATGL induced by $17 \beta-\mathrm{E} 2$ was abolished by ER $\alpha$ antagonist MPP or LPS (Fig. 4).

\section{Discussion}

The accumulation of TG in adipocytes is associated with metabolic diseases including obesity. Ding et al. reported ovariectomy significantly increases adipose tissue mass [6]. Deficiency of aromatase, the enzyme responsible for estrogen biosynthesis, results in increased adiposity [18], indicating estrogen could regulate adipocyte. Zhang et al. [13] reported estradiol inhibits the adipocyte marker genes and adipogenesis. Our present study showed that $17 \beta-E 2$ significantly decreased the TG content in differenced 3T3-L1 cells. 

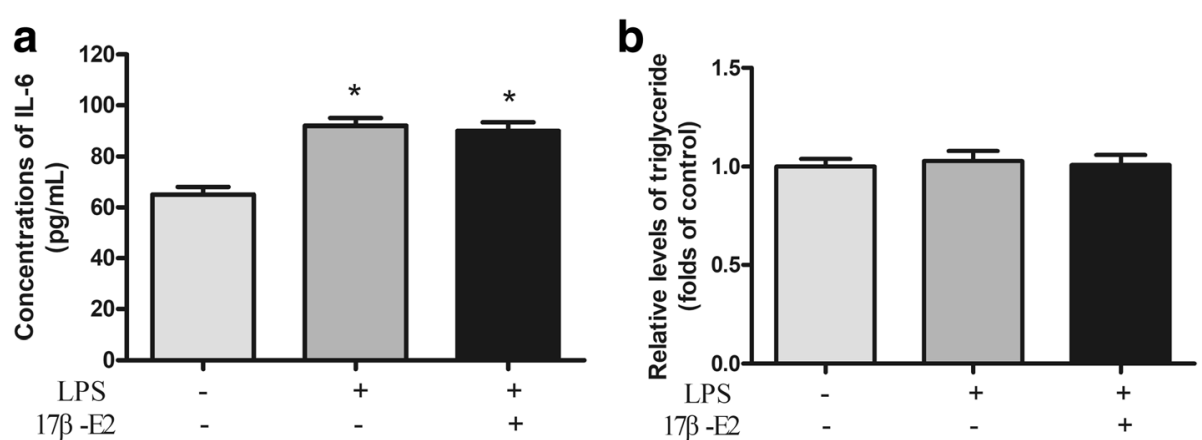

Fig. 3 17ß-E2 did not affect triglyceride content in differentiated 3T3-L1 cells on inflammatory state. Differentiated 3T3-L1 adipocytes were starved in serum free DMEM for $12 \mathrm{~h}$ and then were treated with $0.1 \%$ DMSO alone, $100 \mathrm{ng} / \mathrm{mL}$ LPS (pre-treated for $24 \mathrm{~h}$ then washed with PBS), $100 \mathrm{ng} / \mathrm{mL}$ LPS (pre-treated for $24 \mathrm{~h}$ then washed with PBS) plus $1 \mu \mathrm{M}$ 17ß-E2 for $48 \mathrm{~h}$. Intracellular TG contents were normalized by total protein. a) Concentrations of IL-6; b) Relative levels of triglyceride. The data were presented as the mean $\pm \mathrm{SD}, n=3$ for each group. ${ }^{*} P<0.05$, compared with Control group. LPS: lipopolysaccharide

$E R \alpha$ and ER $\beta$ are the main classical receptors of estrogen and are reported to express in 3T3-L1 cells. Previous studies reported that ER $\alpha$ plays important role in lipids and glucose metabolism [19, 20]. Wend et al. [21] found bone marrow cells from $\mathrm{ER} \alpha$ knockout (KO) mice differentiated to adipocytes in vitro have increased lipid

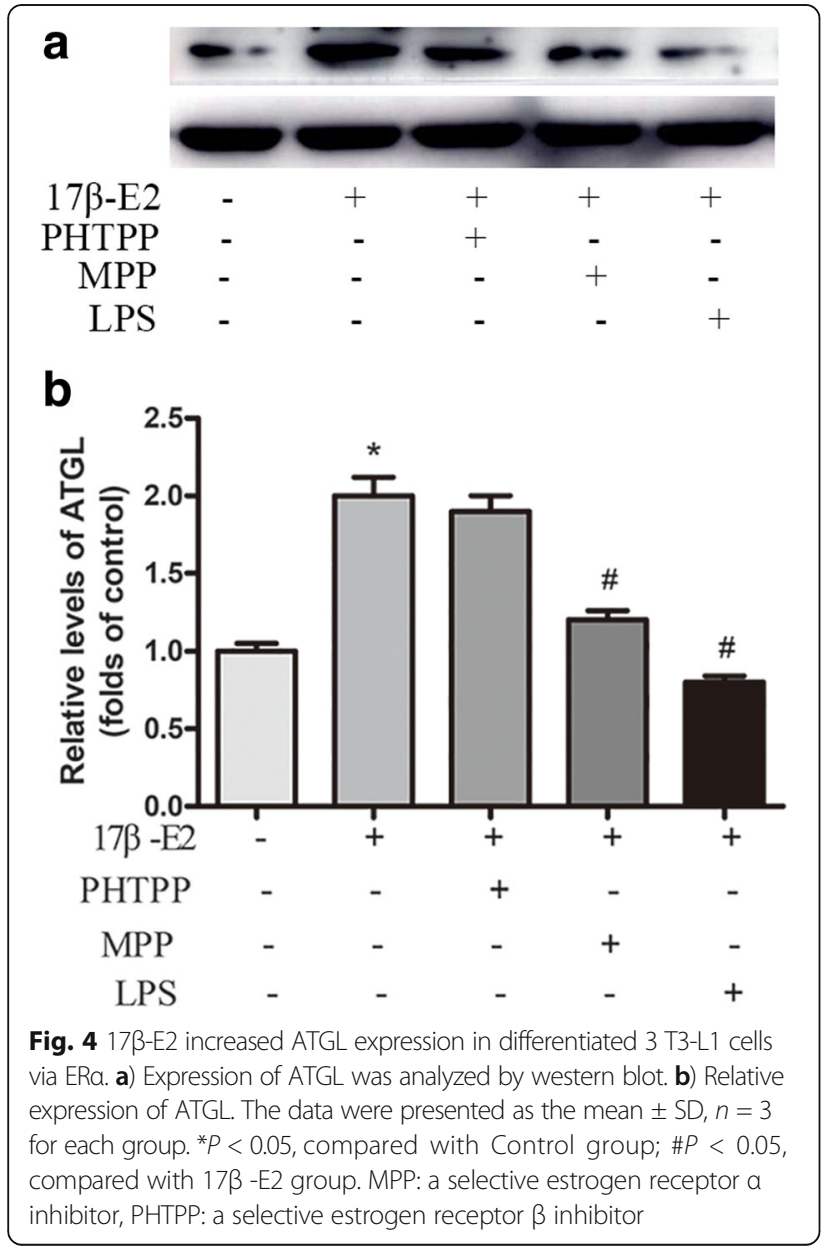

accumulation compared to cells from wild-type mice or ER $\beta$ KO mice. Pedram et al. [22] found $17 \beta-E 2$ bound membrane ER $\alpha$ and then repressed TG contents in differentiated adipocytes. These evidences indicated ER $\alpha$ but not ER $\beta$ plays a pivotal role in estradiol induced TGlowering effect. Our present result, for the first time, found 17 $\beta$-E2 decreased TG through ER $\alpha$ but not ER $\beta$.

ATGL is a key enzyme involved in intracellular degradation of TG. ATGL catalyzes the first step of TG catabolism which hydrolyzes TG in diacylglycerol [23]. Wohlers et al. [24] found expression of ATGL in visceral fat is not affected with estrogen treatment in ovariectomized mice. But, the results of animal experiment may be affected by multiple factors such as the dose and duration of estrogen treatment. We found 17 $\beta$-E2 significantly increased expression of ATGL in vitro. Recent study reported bone marrow cells from $\mathrm{ER} \alpha \mathrm{KO}$ mice differentiated to adipocyte in culture have lower expression of ATGL than wild-type adipocyte and estradiol treatment cannot affect the expression of ATGL [21]. It indicated that estradiol via ER $\alpha$ upregulates ATGL expression. Therefore, 17 $\beta$-E2 may decrease TG accumulation through increasing the expression of ATGL.

Obesity is an important risk factor of atherosclerosis $[25,26]$. Early estradiol replacement therapy in postmenopausal women was demonstrated to be efficient to attenuate the progress of atherosclerosis [27]. However, the Heart and Estrogen/progestin Replacement Study (HERS) and the Estrogen Replacement and Atherosclerosis (ERA) study found estrogen replacement treatment did not reduce risk of cardiovascular events in women with coronary artery atherosclerosis (CAD) [28-30]. Atherosclerosis is a chronic disease of the arterial wall largely driven by inflammation [31]. Previous studies indicated estrogen did not attenuate the progress of atherosclerosis in women who had already developed atherosclerosis $[32,33]$. Therefore, we speculate that inflammation may 
affect the effect of estradiol. In present study, we further evaluated the effect of estradiol on TG contents on inflammatory state induced by LPS. We found that IL-6 levels in feeder cell culture supernatants were significantly increased when 3T3-L1 exposed to LPS, it indicated LPS could induce inflammation. For the first time, we found 17-E2 did not decrease TG contents or increase expression of ATGL in LPS-stimulated adipocytes. The result indicated that the TG-lowering effect in adipocytes is abolished by inflammation. The underlying mechanisms deserve further investigation.

\section{Conclusion}

This study illustrated 17ß-E2 can increase ATGL expression and lower triglycerides in adipose cells via ER $\alpha$ and this effect of $17 \beta-\mathrm{E} 2$ was attenuated by LPS stimulation. It suggests that the TG-regulating effect of $17 \beta-\mathrm{E} 2$ on adipocytes may be affected by inflammation. Further studies are needed to explore the underlying mechanisms.

\section{Abbreviations \\ 17ß-E2: 17ß-estradiol; ATGL: Adipose triglyceride lipase; CAD: Coronary artery disease; DMEM: Dulbecco modified eagle medium; ERA: Estrogen Replacement and Atherosclerosis; ERa: Estrogen receptor a; ERß: Estrogen receptor $\beta$; FBS: Fetal bovine serum; HERS: Heart and Estrogen/progestin Replacement Study; KO: Knockout; LPS: Lipopolysaccharide; TG: Triglyceride}

\section{Acknowledgements}

None.

\section{Funding}

This work was supported by the grants from the Hunan provincial health and Family Planning Commission Scientific Research Foundation of China (No. B2015-019) and the National Natural Science Foundation of China (No.31670816)

\section{Availability of data and materials}

All data generated or analyzed during this study are included in this published article.

\section{Authors' contributions}

$\mathrm{XL}$ conception and design of research; FL, WH and $Y G$ performed experiments; GR and RP analyzed data; FL and WH interpreted results of experiments and prepared figures; FL and GY drafted the manuscript; XL and GR edited and revised manuscript. All authors read and approved the final manuscript.

Ethics approval and consent to participate

Not applicable.

\section{Consent for publication}

Not applicable.

\section{Competing interests}

The authors declare that they have no competing interests.

\section{Publisher's Note}

Springer Nature remains neutral with regard to jurisdictional claims in published maps and institutional affiliations.

\section{Author details}

'Department of Cardiovascular Medicine, The Second Xiangya Hospital, Central South University, No.139 Renmin Middle Road, Changsha 410011 , Hunan, People's Republic of China. 'Department of Emergency Medicine, Yantai Yuhuangding Hospital, Qingdao University Medical College, Yantai, Shangdong 264000, People's Republic of China.
Received: 18 April 2017 Accepted: 20 September 2017

Published online: 25 September 2017

\section{References}

1. Kwasniewska M, Pikala M, Kaczmarczyk-Chalas K, et al. Smoking status, the menopausal transition, and metabolic syndrome in women. Menopause. 2012:19:194-201.

2. Donato GB, Fuchs SC, Oppermann K, et al. Association between menopause status and central adiposity measured at different cutoffs of waist circumference and waist-to-hip ratio. Menopause. 2006;13:280-5.

3. Samaras K, Hayward CS, Sullivan D, et al. Effects of postmenopausal hormone replacement therapy on central abdominal fat, glycemic control, lipid metabolism, and vascular factors in type 2 diabetes: a prospective study. Diabetes Care. 1999;22:1401-7.

4. Meli R, Pacilio M, Raso GM, et al. Estrogen and raloxifene modulate leptin and its receptor in hypothalamus and adipose tissue from ovariectomized rats. Endocrinology. 2004;145:3115-21.

5. Chiang $\mathrm{Tl}$, Chang IC, Lee $\mathrm{HH}$, et al. Amelioration of estrogen deficiency-induced obesity by collagen hydrolysate. Int J Med Sci. 2016;13:853-7.

6. Ding LC, Gong QQ, Li SW, et al. Rcan2 and estradiol independently regulate body weight in female mice. Oncotarget. 2017;8:48098-109.

7. Zheng XY, Zhao SP, Yan $\mathrm{H}$. The role of apolipoprotein $\mathrm{A} 5$ in obesity and the metabolic syndrome. Biol Rev Camb Philos Soc. 2013;88:490-8.

8. Luo F, Guo Y, Ruan GY, et al. Estrogen lowers triglyceride via regulating hepatic APOA5 expression. Lipids Health Dis. 2017;16:72

9. Guo W, Fu J, Chen X, et al. The effects of estrogen on serum level and hepatocyte expression of PCSK9. Metabolism. 2015;64:554-60.

10. Whitcroft SI, Crook D, Marsh MS, et al. Long-term effects of oral and transdermal hormone replacement therapies on serum lipid and lipoprotein concentrations. Obstet Gynecol. 1994;84:222-6.

11. Godsland IF. Effects of postmenopausal hormone replacement therapy on lipid, lipoprotein, and apolipoprotein (a) concentrations: analysis of studies published from 1974-2000. Fertil Steril. 2001;75:898-915.

12. Han SI, Komatsu Y, Murayama A, et al. Estrogen receptor ligands ameliorate fatty liver through a nonclassical estrogen receptor/Liver $X$ receptor pathway in mice. Hepatology. 2014;59:1791-802

13. Zhang R, Su D, Zhu W, et al. Estrogen suppresses adipogenesis by inhibiting S100A16 expression. J Mol Endocrinol. 2014;52:235-44.

14. Hotamisligil GS. Inflammation and metabolic disorders. Nature. 2006:444: 860-7.

15. Chen $Y$, Chen $M, W u Z$, et al. Ox-LDL induces ER stress and promotes the adipokines secretion in 3T3-L1 adipocytes. PLoS One. 2013;8:e81379.

16. Luo F, Guo Y, Ruan GY, et al. Combined use of metformin and atorvastatin attenuates atherosclerosis in rabbits fed a high-cholesterol diet. Sci Rep. 2017;7:2169.

17. Ruparelia N, Chai JT, Fisher EA, et al. Inflammatory processes in cardiovascular disease: a route to targeted therapies. Nat Rev Cardiol. 2017;14:133-44.

18. Jones ME, Thorburn AW, Britt KL, et al. Aromatase-deficient (ArKO) mice have a phenotype of increased adiposity. Proc Natl Acad Sci U S A. 2000;97: 12735-40.

19. Davis KE. M DN, Sun K, et al. The sexually dimorphic role of adipose and adipocyte estrogen receptors in modulating adipose tissue expansion, inflammation, and fibrosis. Mol Metab. 2013;2:227-42.

20. Yasrebi A, Rivera JA, Krumm EA, et al. Activation of Estrogen Response Element-Independent ERalpha Signaling Protects Female Mice From Diet-Induced Obesity. Endocrinology. 2017;158:319-34.

21. Wend $K$, Wend $P$, Drew $B G$, et al. ERalpha regulates lipid metabolism in bone through ATGL and perilipin. J Cell Biochem. 2013;114:1306-14.

22. Pedram A, Razandi M, Blumberg B, et al. Membrane and nuclear estrogen receptor alpha collaborate to suppress adipogenesis but not triglyceride content. FASEB J. 2016:30:230-40.

23. Fruhbeck G, Mendez-Gimenez L, Fernandez-Formoso JA, et al. Regulation of adipocyte lipolysis. Nutr Res Rev. 2014;27:63-93.

24. Wohlers LM, Spangenburg EE. 17beta-estradiol supplementation attenuates ovariectomy-induced increases in ATGL signaling and reduced perilipin expression in visceral adipose tissue. J Cell Biochem. 2010;110:420-7.

25. Lovren F, Teoh H, Verma S. Obesity and atherosclerosis: mechanistic insights. Can J Cardiol. 2015;31:177-83.

26. Wu ZH, Zhao SP. Adipocyte: a potential target for the treatment of atherosclerosis. Med Hypotheses. 2006;67:82-6. 
27. Hodis HN, Mack WJ, Henderson WW, et al. Vascular Effects of Early versus Late Postmenopausal Treatment with Estradiol. N Engl J Med. 2016;374: 1221-31.

28. Grady D, Herrington D, Bittner $V$, et al. Cardiovascular disease outcomes during 6.8 years of hormone therapy: Heart and Estrogen/progestin Replacement Study follow-up (HERS II). JAMA. 2002;288:49-57.

29. Herrington DM, Reboussin DM, Brosnihan KB, et al. Effects of estrogen replacement on the progression of coronary-artery atherosclerosis. N Engl J Med. 2000;343:522-9.

30. Herrington DM, Reboussin DM, Klein KP, et al. The estrogen replacement and atherosclerosis (ERA) study: study design and baseline characteristics of the cohort. Control Clin Trials. 2000;21:257-85.

31. Verweij SL, van der Valk FM, Stroes ES. Novel directions in inflammation as a therapeutic target in atherosclerosis. Curr Opin Lipidol. 2015;26:580-5.

32. Clarkson TB. Estrogen effects on arteries vary with stage of reproductive life and extent of subclinical atherosclerosis progression. Menopause. 2007;14: 373-84.

33. Rosenfeld ME, Kauser K, Martin-McNulty B, et al. Estrogen inhibits the initiation of fatty streaks throughout the vasculature but does not inhibit intra-plaque hemorrhage and the progression of established lesions in apolipoprotein $E$ deficient mice. Atherosclerosis. 2002;164:251-9.

\section{Submit your next manuscript to BioMed Central and we will help you at every step:}

- We accept pre-submission inquiries

- Our selector tool helps you to find the most relevant journal

- We provide round the clock customer support

- Convenient online submission

- Thorough peer review

- Inclusion in PubMed and all major indexing services

- Maximum visibility for your research

Submit your manuscript at www.biomedcentral.com/submit 